\title{
BMJ Open Socioeconomic status and cigarette expenditure among US households: results from 2010 to 2015 Consumer Expenditure Survey
}

\author{
Mohammad Siahpush, ${ }^{1}$ Paraskevi A Farazi, ${ }^{2}$ Shannon I Maloney, ${ }^{1}$ Danae Dinkel, ${ }^{3}$ \\ Minh N Nguyen, ${ }^{2}$ Gopal K Singh ${ }^{4}$
}

To cite: Siahpush $\mathrm{M}$, Farazi PA, Maloney SI, et al. Socioeconomic status and cigarette expenditure among US households: results from 2010 to 2015 Consumer Expenditure Survey. BMJ Open 2018;8:e020571. doi:10.1136/ bmjopen-2017-020571

- Prepublication history for this paper is available online. To view these files, please visit the journal online (http://dx.doi. org/10.1136/bmjopen-2017020571).

Received 10 November 2017 Revised 27 April 2018 Accepted 15 May 2018

Check for updates

${ }^{1}$ Department of Health Promotion, College of Public Health, University of Nebraska Medical Center, Omaha, Nebraska, USA

${ }^{2}$ Department of Epidemiology, College of Public Health, University of Nebraska Medical Center, Omaha, Nebraska, USA ${ }^{3}$ School of Health and Kinesiology, College of Education, University of Nebraska, Omaha, Nebraska, USA

${ }^{4}$ U.S. Department of Health \& Human Services, Office of Health Equity, Health Resources and Services Administration, Rockville, Maryland, USA

Correspondence to Dr Mohammad Siahpush; msiahpush@unmc.edu

\section{ABSTRACT}

Objectives To examine (1) the association between household socioeconomic status (SES) and whether a household spends money on cigarettes and (2) socioeconomic variations in proportion of total household expenditure spent on cigarettes among smoking households.

Methods We pooled data from six consecutive years, 2010-2015, of the Consumer Expenditure Interview Survey. The interviews involved a structured questionnaire about household income, demographics and expenditures including expenditure on cigarettes. Households that reported cigarette expenditure in the previous 3 months were distinguished as smoking households. SES indicators were household poverty status, education and occupation of the head of household. Logistic regression was used to assess the association of household smoking status with SES. Fractional logistic regression was used to assess the association of cigarette expenditure as a proportion of total household expenditure with SES. The analysis sample size was 39218.

Results The probability of spending money on cigarettes was higher among lower SES households. Households in poverty compared with those above $300 \%$ of poverty threshold had 1.86 (95\% $\mathrm{Cl} 1.61$ to 2.16 ), households headed by a person with less than high school education compared with those headed by a person with at least a bachelor's degree had 3.37 (95\% Cl 2.92 to 3.89 ) and households headed by a blue-collar work compared with those headed by a person in a managerial occupation had $1.45(95 \% \mathrm{Cl} 1.26$ to 1.66$)$ higher odds of spending money on cigarettes. Similarly, the proportion of total household expenditure spent on cigarettes was higher among lower SES smoking households.

Conclusion Lower SES households are more likely to spend money on cigarettes and spend a larger proportion of their total expenditure on cigarettes. We recommend strategies effective in reducing smoking among low SES smokers.

\section{INTRODUCTION}

Smoking cigarettes causes numerous health conditions, ${ }^{1}$ and is associated with deleterious financial consequences and a lowered standard
Strengths and limitations of this study

- We used a national household survey representing the entire US civilian non-institutional population that involved a structured questionnaire to collect data on household income, demographics and a complete range of expenditures.

- Conclusions are based on data from six consecutive years of national and comprehensive expenditure data with relatively high response rates and large sample sizes.

- The cross-sectional design does not allow for causal inferences about the relationship between socioeconomic status and whether a household spends money on cigarettes or per cent of household expenditure spent on cigarettes among smoking households.

of living. For example, smokers compared with non-smokers are more likely to experience financial stress, defined as events such as going without meals or not being able to pay rent. ${ }^{2}$ Similarly, among smokers, higher cigarette expenditure is associated with a higher probability of experiencing financial stress. ${ }^{3}$ Furthermore, smokers who spend more on cigarettes are more likely to report 'smoking-induced deprivation', measured by asking smokers whether 'money ... spent on cigarettes resulted in not having enough money for household essentials such as food'. ${ }^{34}$ There is also evidence that quitting smoking is associated with a subsequent reduction in the probability of experiencing financial stress ${ }^{56}$ and an increased level of prosperity. ${ }^{5}$

One of the strong and persistent determinants of smoking behaviour in developed countries is socioeconomic status (SES). ${ }^{7-12}$ For example, in the USA, in 2015, smoking prevalence among adults living below the poverty line was nearly two times that of those at or above the poverty line (26.1\% vs $13.9 \%)$. 
Similarly, smoking prevalence among individuals aged 25 years or older ranged from $34.1 \%$ in persons with a high school diploma to $16.6 \%$ in those with an associate degree to only $3.6 \%$ in those with a graduate degree. ${ }^{9}$

There are numerous studies documenting the association between SES and smoking behaviour. Less has been published on the association between SES and expenditure on cigarettes. Whereas the primary implication of studies of the SES determinants of smoking pertains to the deleterious health effects of smoking and health inequalities, the primary implication of studies of cigarette expenditure relates to the financial burden of smoking. ${ }^{313-15} \mathrm{An}$ expenditure study conducted in Australia used data from a sample of 6892 households and showed that those with a lower SES were more likely to report tobacco expenditure. ${ }^{16}$ The odds of tobacco expenditure were 2.3 times greater among households headed by a person with no educational qualification than a university degree and 1.4 times greater among households headed by a person with a bluecollar occupation than a professional occupation. Furthermore, among smoking households, those with a lower SES spent a higher proportion of their funds on tobacco. Per cent of total household expenditure spent on tobacco was $46 \%$ higher among households headed by a person with no educational qualification than a university degree and 38\% higher among households headed by a person with a blue-collar occupation than a professional occupation. A different study of 1144 households in Sri Lanka revealed that while higher income households spent more on tobacco products, they had a lower tobacco expenditure as a percentage of total household expenditure. ${ }^{13}$ Similar results were reported in a study conducted in the Russian Federation, Azerbaijan, Georgia, Kazakhstan, Kyrgyzstan, Tajikistan ${ }^{15}$ and another in Morocco. ${ }^{14}$ Finally, a study of 748 smokers in the USA showed that lower income households spent a higher percentage of their household income on cigarettes. ${ }^{17}$ This study did not assess the association of other commonly used indicators of SES (eg, education and occupation) with cigarette expenditure. Furthermore, the study did not adjust for the effect of possible confounders in assessing the relationship between income and per cent of income spent on cigarettes. Finally, the study did not measure cigarette expenditure directly; instead, it was estimated indirectly by asking respondents how many cigarettes they smoked each day and the price they paid for their last pack of cigarettes. Our aim was to address these shortcomings. We used data from the Consumer Expenditure Survey (CES) in the USA to examine (1) the association between household SES and whether a household reports cigarette expenditure and (2) SES variations in proportion of total household expenditure spent on cigarettes among smoking households.

\section{METHODS}

\section{Data}

We used data from the CES, which is conducted by the US Census Bureau under contract with the Bureau of
Labor Statistics. ${ }^{18}$ The CES is a national household survey representing the entire US civilian non-institutional population. The CES uses a cluster sampling design where primary sampling units (PSUs) are small clusters of counties grouped together into geographical entities. The sampling frame within the PSUs is the Census Bureau's Master Address File, which contains residential addresses identified in the 2010 census. Approximately, 6900 households at the identified addresses are interviewed each quarter of the year. Each household is interviewed every 3 months over four calendar quarters. After the fourth interview, the household is dropped from the survey and replaced by a new sample. The response rates varied from the highest of $74.5 \%$ in 2010 to the lowest of $64.2 \%$ in $2015 .^{19}$ The interviews' duration was about $60 \mathrm{~min}$ and they were primarily conducted in person using a structured questionnaire to collect data on household income, demographics and a complete range of expenditure items. We appended data from the third quarter data collection (ie, July, August and September) of six consecutive years, 2010-2015, with a total sample size of 39806 households. Each household appears only once in the pooled dataset. We did not use the first quarter data because the expenditure report of some of the participants pertained to the previous calendar year. Our sensitivity analyses revealed that using data from the second and fourth quarter yields very similar results as we report in this article. We excluded from the analysis 588 households, that is, $1.5 \%$ of the total number of households, for which there was a missing value for one or more study variables except income. While the amount of missing data was negligible and not likely to have biased the results, we note that households with missing data were more likely to be of a higher SES background and report cigarette expenditure. The final sample size for the analysis was 39218. Ethical approval was not needed for this study as we used secondary data that are publicly available by the US Bureau of Statistics.

\section{Measurement of smoking status of households and cigarette expenditure as a proportion of total household expenditure}

The head of household, who is the first person mentioned by a respondent to be the one who owns or rents the home of the household, ${ }^{2021}$ was asked: "since the first of the reference month [three months prior to the interview], have you or any members of your household purchased cigarettes?' An affirmative answer indicated a smoking household. The head of a smoking household was asked: 'What is the usual weekly expense for cigarettes?' Weekly cigarette expenditure amounts were converted to quarterly amounts by the Census Bureau to match the time frame for the reporting of most other household expenditures items. We converted nominal expenditure amounts to constant 2015 dollars using the commonly used all-items Consumer Price Index to account for inflation. ${ }^{22}{ }^{23}$ For smoking households, we computed cigarette expenditure as a proportion of total expenditure including expenditure on items such as food, alcoholic beverages, tobacco 
and smoking supplies, housing, apparel, transportation, healthcare, entertainment, and personal care.

\section{Measurement of SES and other covariates}

We employed three SES indicators: household poverty status, education and occupation of head of household. We defined poverty status as the ratio of household income to poverty threshold for a given family size and composition for each survey year. ${ }^{24}$ Regression-based multiple imputation was used by the Census Bureau to replace missing household income data. ${ }^{25}$ We categorised education of the head of household into four groups as follows: less than high school, high school graduate, some college or associate degree and bachelor's or higher degree. We categorised occupation of the head of household into five groups as follows: manager and professional, administrative support, technician, sales, service, including cleaning and building service, health service, food and beverage preparation, and protective and private household service, blue collar, including machine and transportation operator, handler, labourer, mechanic and construction worker, other occupations and not in the labour force.

Other covariates used in the models were as follows: race/ethnicity of head of household, categorised as non-Hispanic white, non-Hispanic black, Hispanic and other, household size, number of males aged 16 and over in the household, number of females aged 16 and over in the household and survey year.

\section{Statistical analysis}

The unit of analysis in this study was the household. US Department of Labor provides sampling weights for each CES survey quarter. These weights were computed based on the probability of selection of a household, household non-response and national household distribution of age, race and region. ${ }^{18}$ In order to combine 6 years of surveys, we created an adjusted weight by multiplying the original weight in a given survey to the ratio of the sample size for that survey and the sum of samples sizes of all six surveys. ${ }^{26}$ We used this adjusted weight for the computation of all point estimates and in all analyses.

The US Department of Labor also provides 44 replicate samples with accompanying sampling weights for SE estimation. ${ }^{18}$ Using replicate samples to estimate an SE involves computing a statistic for subsets of the full study sample and examining the variability of the statistic over the subsets. ${ }^{27}$ In essence, this method allows a single sample to simulate multiple samples. Replicate samples were constructed using the 'balanced repeated replication' method where the sampled PSUs were divided into 44 strata and the households within each stratum were randomly divided into two half samples. CES uses a $44 \times 44$ Hadamard matrix to create the replicates in a 'balanced' way. ${ }^{28}$ Once the subsamples were formed, survey weights were computed for each subsample using the method described above for the weights for each CES survey quarter. Subsequently, 44 different estimates of a statistic were generated using only one half-sample per stratum. These estimates were then used to approximate SEs based on the formula for computing sample SD:

$$
\sigma_{\theta}=\sqrt{\frac{1}{44} \sum_{r=1}^{44}\left(\theta_{r}-\theta\right)^{2}}
$$

where $\theta$ is the estimated statistic based on the full sample, $\sigma_{\theta}$ is the $\mathrm{SE}$ of $\theta$ and $\theta_{r}$ is the rth replicate estimate of $\theta$. We used this data-dependent method of estimating SEs which is especially useful when data are generated through a multistage sampling design and where, to preserve respondent anonymity, complete information on sample clusters or strata is not made available to researchers as is the case in CES. ${ }^{29}$

We first conducted preliminary analyses to assess the bivariable associations of household smoking status and cigarette expenditure as a proportion of total household expenditure with each predictor. Subsequently, we used binary response logistic regression to assess the association of household smoking status and SES indicators. We also used fractional response logistic regression to assess the association of cigarette expenditure as a proportion of total household expenditure with SES indicators. ${ }^{30-32}$ Fractional models are suitable for doubly bounded continuous variables such as proportions. The results of these models can be presented as relative proportion ratios. ${ }^{30}$ We checked for the normality of residuals and multicollinearity and found no violation of these ordinary least squares regression assumptions in the multivariable model. In relation to the issue of multicollinearity, we note that the associations between poverty status and education (Kendall's tau- $b=0.34$ ), poverty status and occupation (Cramer's V=0.27), and education and occupation (Cramer's V $=0.27$ ) were moderate. Furthermore, the largest change in an SE comparing bivariable and multivariable regression results was $29.3 \%$ and pertained to the dummy variable comparing households in poverty with those at or above $300 \%$ of poverty line in the binary response logistic regression. Covariates whose $\mathrm{p}$ values were greater than 0.1 in the bivariable models were not included in the multivariable models. We used Stata V.14.1 for all analyses. ${ }^{33}$

\section{Patient and public involvement}

Patients and public were not involved.

\section{RESULTS}

\section{Sample characteristics and bivariable associations}

Table 1 provides weighted sample characteristics and bivariable associations between the covariates and the outcomes. Overall, $17.4 \%$ of households reported expenditure on cigarettes. Among smoking households, the mean quarterly expenditure on cigarettes in constant 2015 dollars was US\$458 and the mean cigarette expenditure as a percentage of total household expenditure was $5.6 \%$. About $14.6 \%$ of the households lived below the 
Table 1 Weighted sample characteristics, bivariable association of smoking status of households and covariates ( $n=39218)$, and bivariable association of cigarette expenditure and covariates among smoking household $(n=6559)$

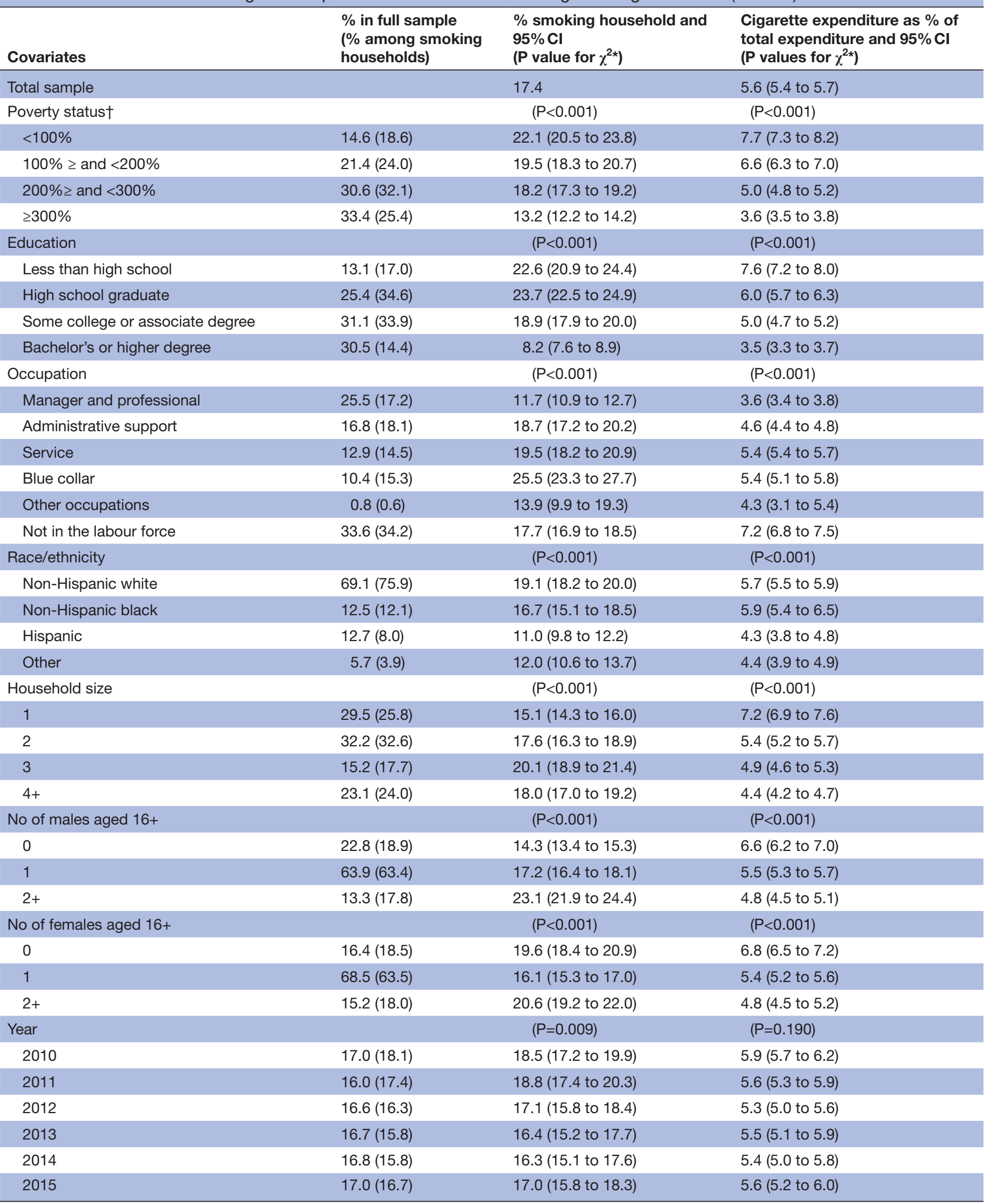

${ }^{*} \mathrm{P}$ values for the bivariable association of covariates and each of the three outcomes using 44 replicate weights.

†Higher percentages indicate higher relative income. 
poverty threshold and $38.5 \%$ of the heads of households did not report a level of education beyond high school graduation. About $25.5 \%$ of the households were headed by a person holding a managerial or professional occupation, $16.8 \%$ by a person with an administrative occupation, $12.9 \%$ by a person holding a service occupation and $10.4 \%$ by a person in a blue-collar occupation. The percentage of non-Hispanic whites, non-Hispanic blacks and Hispanics were $69.1 \%, 12.5 \%$ and $12.7 \%$, respectively. Table 1 also shows that compared with all households, smoking household had a higher percentage from lower SES backgrounds.

At the bivariable level, poorer households, those headed by a person with a lower level of education, and those headed by a person with a lower occupational status (such as blue collar, service or administrative compared with managerial or professional occupations) had a higher probability of being a smoking household. For example, while $22.1 \%$ of households below poverty reported cigarette expenditure, only $13.2 \%$ of those at or above $300 \%$ of poverty threshold did so. Similarly, while the percentage of smoking households was $22.6 \%$ among households headed by a person who did not complete high school, that percentage was only $8.2 \%$ among households headed by a college graduate. Furthermore, while $25.5 \%$ of household headed by a blue-collar person reported cigarette expenditure, only $11.7 \%$ of those headed by a person in a managerial or professional occupation did so.

Bivariable results also provide strong evidence that poorer households, those headed by a person with a lower level of education or lower occupational status had a higher percentage of their total expenditure devoted to cigarette expenditure.

\section{Multivariable analyses}

Table 2 shows adjusted ORs and 95\% CIs for the association of being a smoking household and SES indicators. Poorer households, those headed by a person with a lower level of education or lower occupational status were more likely to report cigarette expenditure $(\mathrm{p}<0.001$ for poverty, education and occupation). The OR comparing households in poverty with those above $300 \%$ of poverty threshold was $1.86(95 \%$ CI 1.61 to 2.16 ). Similarly, the OR comparing households headed by a person who did not complete high school with those headed by a person with at least a bachelor's degree was 3.37 (95\% CI 2.92 to 3.89). Furthermore, the OR comparing households headed by a blue-collar worker with those headed by a person in a managerial or professional occupation was 1.45 (95\% CI 1.26 to 1.66). Race/ethnicity was associated with smoking status $(\mathrm{p}<0.001)$ such that the odds of being a smoking household were largest among households headed by a non-Hispanic white person and lowest among those headed by a Hispanic individual. Larger households $(p<0.001)$, those with more males 16 years or older $(p<0.001)$, and those with fewer females 16 years or older $(p=0.036$ ) had higher odds of reporting cigarette expenditure. Finally, there was some evidence that the odds of being a smoking household were greater in 2010 and 2011 than in later years $(\mathrm{p}=0.036)$.

Table 2 also shows the results of the fractional logit regression for modelling the association of cigarette expenditure as a proportion of total household expenditure with SES and other covariates, among smoking households. Poorer households, those headed by a person with a lower level of education or a lower occupational status had a higher cigarette expenditure as a proportion of total household expenditure. The relative proportion ratio comparing households in poverty with those above $300 \%$ of poverty threshold was $1.74(95 \%$ CI 1.62 to 1.87 ). Similarly, the relative proportion ratio comparing households headed by a person who did not complete high school with those headed by a person with at least a bachelor's degree was 1.80 (95\% CI 1.65 to 1.96). Furthermore, the relative proportion ratio comparing households headed by a blue-collar worker with those headed by a person in a managerial or professional occupation was 1.16 (95\% CI 1.06 to 1.27). Race/ethnicity was associated with proportion spent on cigarettes such that households headed by a non-Hispanic white person had the highest and those headed by a Hispanic individual had the lowest proportion spent on cigarettes $(p<0.001)$. Larger households had a lower proportion spent on cigarettes $(\mathrm{p}<0.001)$.

\section{DISCUSSION}

In this study, we pooled data from six consecutive years of the US CES and found that lower SES households are more likely to spend money on cigarettes and spend a larger portion of their total household expenditure on cigarettes. Our results were consistent with a previous report in the USA ${ }^{17}$ and the findings from other countries, although these findings pertained to the general category of tobacco expenditure and not specifically to cigarette expenditure. ${ }^{13-16}$

We also found that larger households and households headed by a non-Hispanic white person compared with others had a higher probability of reporting cigarette expenditure and spent a larger proportion of their total household expenditure on cigarettes. Furthermore, households with a larger number of males aged $16+$ years and those with fewer females aged $16+$ years had a higher probability of reporting cigarette expenditure. None of these covariates, except number of males and females in the household, have been previously investigated in regard to tobacco expenditure. Our findings about number of males and females were not consistent with a study that was conducted in the Russian Federation, Azerbaijan, Georgia, Kazakhstan, Kyrgyzstan and Tajikistan, ${ }^{15}$ where the number of males was positively and the number of females was negatively associated with tobacco expenditure as a share of total household expenditure. 
Table 2 Multivariable results ${ }^{*}$ for the association of smoking status of household and cigarette expenditure as a proportion of total household expenditure with socioeconomic status indicators and other covariates

\begin{tabular}{|c|c|c|c|c|}
\hline \multirow[b]{2}{*}{ Covariates } & \multicolumn{2}{|c|}{$\begin{array}{l}\text { Odds of being a smoking household } \\
(n=39218)\end{array}$} & \multicolumn{2}{|c|}{$\begin{array}{l}\text { Cigarette expenditure as a proportion of } \\
\text { household expenditure }(n=6559)\end{array}$} \\
\hline & Adjusted ORs (95\% Cl) & $P$ values & $\begin{array}{l}\text { Adjusted relative proportion ratios } \\
(95 \% \mathrm{Cl})\end{array}$ & $P$ values \\
\hline Poverty status & & $<0.001$ & & $<0.001$ \\
\hline$<100 \%$ & 1.86 (1.61 to 2.16$)$ & & 1.74 (1.62 to 1.87$)$ & \\
\hline $100 \% \geq$ and $<200 \%$ & $1.46(1.29$ to 1.65$)$ & & 1.57 (1.46 to 1.69$)$ & \\
\hline$\geq 300 \%$ & 1.00 & & 1.00 & \\
\hline Education & & $<0.001$ & & $<0.001$ \\
\hline Less than high school & 3.37 (2.92 to 3.89 ) & & 1.80 (1.65 to 1.96$)$ & \\
\hline High school graduate & $3.02(2.72$ to 3.35$)$ & & 1.50 (1.37 to 1.63$)$ & \\
\hline Some college or associate degree & 2.31 (2.11 to 2.54$)$ & & 1.28 (1.18 to 1.39$)$ & \\
\hline Administrative support & 1.20 (1.09 to 1.32$)$ & & 1.05 (0.97 to 1.14$)$ & \\
\hline Service & 1.20 (1.09 to 1.33$)$ & & 1.16 (1.07 to 1.26$)$ & \\
\hline Blue collar & 1.45 (1.26 to 1.66$)$ & & 1.16 (1.06 to 1.27$)$ & \\
\hline Other occupations & $0.68(0.44$ to 1.04$)$ & & $0.90(0.71$ to 1.13$)$ & \\
\hline Not in the labour force & $0.92(0.82$ to 1.03$)$ & & $1.33(1.25$ to 1.41$)$ & \\
\hline Race/ethnicity & & $<0.001$ & & $<0.001$ \\
\hline Non-Hispanic white & 1.00 & & 1.00 & \\
\hline Non-Hispanic black & 0.65 (0.57 to 0.46$)$ & & 0.88 (0.81 to 0.95$)$ & \\
\hline Hispanic & 0.31 (0.78 to 0.35$)$ & & $0.68(0.60$ to 0.77$)$ & \\
\hline No of males aged $16+$ & & $<0.001$ & & 0.085 \\
\hline 0 & 1.00 & & 1.00 & \\
\hline 1 & 1.17 (1.06 to 1.29$)$ & & 1.04 (0.95 to 1.13$)$ & \\
\hline $2+$ & 1.60 (1.40 to 2.09$)$ & & 1.11 (0.99 to 1.24$)$ & \\
\hline No of females aged $16+$ & & 0.036 & & 0.867 \\
\hline 0 & 1.00 & & 1.00 & \\
\hline 1 & 0.73 (0.65 to 0.83 ) & & 0.99 (0.90 to 1.09$)$ & \\
\hline $2+$ & $0.92(0.80$ to 1.05$)$ & & $1.01(0.88$ to 1.16$)$ & \\
\hline Year & & 0.036 & & - \\
\hline 2010 & 1.00 & & - & \\
\hline 2011 & $1.02(0.93$ to 1.11$)$ & & - & \\
\hline 2012 & $0.92(0.83$ to 1.00$)$ & & - & \\
\hline 2013 & 0.88 (0.78 to 0.99$)$ & & - & \\
\hline 2014 & 0.88 (0.79 to 0.98$)$ & & - & \\
\hline 2015 & 0.95 (0.85 to 1.06$)$ & & - & \\
\hline
\end{tabular}

*All ORs from logistic analysis and regression coefficients $(\beta)$ from linear regression analyses are adjusted for the effect of all covariates in the model. 
A strength of this work was its use of six consecutive years of national and comprehensive expenditure data with relatively high response rates and large sample sizes. The validity of the CES data has been investigated by comparing them with National Income and Product Accounts data. ${ }^{34}$ While this comparison was not specifically done for cigarette expenditure, the findings showed that most of the large categories of consumption were measured well in the CES, as the ratio to the National Income and Accounts statistics was close to one and has not declined notably over time. ${ }^{34}$ The major weakness of the study is that, as it is the case with all cross-sectional analyses, it does not allow causal inferences. It is plausible that poorer households headed by a person with a low level of formal education are more likely to have one or more smokers in the household and spend money on cigarettes. The effect of SES on smoking has been extensively studied. ${ }^{75-39}$ It is also plausible that households that spend money on cigarettes and have higher healthcare expenditures due to smoking are more likely to have reduced income and experience downward socioeconomic mobility. However, to our knowledge, the effect of smoking on downward mobility has not been studied. Another weakness of this work is that, as reported in a study where households in the CES were linked to zip codelevel average income, the very high-income households are less likely to respond to the survey. ${ }^{40}$ However, non-response rates were not associated with income over most of the income distribution. ${ }^{40}$ Finally, we note that we did not have a reliable variable for survey mode to include in the analyses. Telephone surveys are associated with under-reporting of smoking ${ }^{41}{ }^{42}$ and based on the extent to which survey mode is associated with SES, the results of this study could be biased.

Cigarette expenditure may contribute to financial deprivation and lower standards of living, which in turn can lead to unfavourable smoking behaviours and outcomes. ${ }^{3} 4{ }^{43-45}$ For example, financial stress is associated with a lower probability of smoking cessation among smokers and a higher probability of relapse among ex-smokers. ${ }^{43}$ Moreover, while smokers with financial stress are more likely to have an interest in quitting, they are less likely to make a quit attempt or succeed in quitting. ${ }^{46}$ In light of our finding that lower SES households are more likely to include a smoker and spend relatively more on cigarettes, we recommend tobacco control policies that are effective in reducing smoking among lower SES groups. Increasing taxation on cigarettes is the most effective policy for reducing smoking among all segments of the population. In fact, many studies have shown that increasing the price of cigarettes results in a larger decrease in smoking prevalence among lower income and occupational groups than others. ${ }^{7} 48$ This policy, however, is likely to negatively affect the finances of low-income smokers who fail to quit or reduce smoking. To address this problem, part or all of the revenues from increased taxation can be used to fund evidencebased smoking cessation programs ${ }^{49}$ for these smokers.
Moreover, there is evidence that the effectiveness of increased taxation can be undermined by the availability of cheap tobacco and that changing the tobacco tax structure for cheap tobacco may promote quitting among low-income groups. ${ }^{50} 51$ In addition to increasing taxation, there is evidence that antismoking mass media campaigns are also effective in reducing smoking prevalence ${ }^{5253}$ and increasing cessation rates ${ }^{54}$ among low SES smokers. Furthermore, it has been reported that plain packaging of and featuring large health warning labels on cigarette packs are associated with reduced positive brand image and intention to purchase cigarettes among socioeconomically disadvantaged smokers. ${ }^{55}$ Finally, there is some evidence that bans on smoking in public places are effective in reducing smoking prevalence and consumption among lower SES smokers ${ }^{56}$ and across all socioeconomic groups. ${ }^{58}$

Contributors MS: conception, design, data acquisition, using Stata for data analysis, interpretation of data, drafting and critical revision. PAF, SIM and DD: conception, data analysis, interpretation of data and critical revision. MNN: design, data analysis, interpretation of data, drafting and critical revision. GKS: conception, data analysis and critical revision. All authors approved the final version as submitted. All authors are accountable for all aspects of the work.

Funding This research received no specific grant from any funding agency in the public, commercial or not-for-profit sectors.

Competing interests None declared.

Patient consent Not required.

Ethics approval None.

Provenance and peer review Not commissioned; externally peer reviewed.

Data sharing statement No additional data are available.

Author note Please change corresponding author to Dr. Mohammad Siahpush (email: msiahpush@unmc.edu)

Open access This is an open access article distributed in accordance with the Creative Commons Attribution Non Commercial (CC BY-NC 4.0) license, which permits others to distribute, remix, adapt, build upon this work non-commercially, and license their derivative works on different terms, provided the original work is properly cited and the use is non-commercial. See: http://creativecommons.org/ licenses/by-nc/4.0/

(c) Article author(s) (or their employer(s) unless otherwise stated in the text of the article) 2018. All rights reserved. No commercial use is permitted unless otherwise expressly granted.

\section{REFERENCES}

1. U.S. Department of Health Human Services. The health consequences of smoking - 50 years of progress: a report of the Surgeon General. 17. Atlanta, GA: US Department of Health and Human Services, Centers for Disease Control and Prevention, National Center for Chronic Disease Prevention and Health Promotion, Office on Smoking and Health, 2014.

2. Siahpush M, Borland R, Scollo M. Smoking and financial stress. Tob Control 2003;12:60-6.

3. Siahpush M, Borland R, Yong HH, et al. Tobacco expenditure, smoking-induced deprivation and financial stress: results from the International Tobacco Control (ITC) Four-Country Survey. Drug Alcohol Rev 2012;31:664-71.

4. Siahpush M, Thrasher JF, Yong HH, et al. Cigarette prices, cigarette expenditure and smoking-induced deprivation: findings from the International Tobacco Control Mexico survey. Tob Control 2013;22:223-6.

5. Siahpush M, Spittal M, Singh GK. Association of smoking cessation with financial stress and material well-being: results from a prospective study of a population-based national survey. Am J Public Health 2007;97:2281-7. 
6. Siahpush M, Spittal M, Singh GK. Smoking cessation and financial stress. J Public Health 2007;29:338-42.

7. Hiscock R, Bauld L, Amos A, et al. Socioeconomic status and smoking: a review. Ann N Y Acad Sci 2012;1248:107-23.

8. Garrett BE, Dube SR, Trosclair A, et al. Cigarette smoking-United States, 1965-2008. MMWR Surveill Summ 2011;60:109-13.

9. Jamal A, King BA, Neff LJ, et al. Current cigarette smoking among adults - United States, 2005-2015. MMWR Morb Mortal Wkly Rep 2016;65:1205 1211.

10. Siahpush M, Borland R. Socio-demographic variations in smoking status among Australians aged > or $=18$ : multivariate results from the 1995 National Health Survey. Aust N Z J Public Health 2001;25:438-42.

11. Nagelhout GE, de Korte-de Boer D, Kunst AE, et al. Trends in socioeconomic inequalities in smoking prevalence, consumption, initiation, and cessation between 2001 and 2008 in the Netherlands. Findings from a national population survey. BMC Public Health 2012;12:303.

12. Hiscock R, Bauld L, Amos A, et al. Smoking and socioeconomic status in England: the rise of the never smoker and the disadvantaged smoker. J Public Health 2012;34:390-6.

13. Perera KM, Guruge GN, Jayawardana PL. Household expenditure on tobacco consumption in a poverty-stricken rural district in Sri Lanka. Asia Pac J Public Health 2017;29:140-8.

14. Tachfouti N, Berraho M, Elfakir S, et al. Socioeconomic status and tobacco expenditures among Moroccans: results of the "Maroc Tabagisme" survey. Am J Health Promot 2010;24:334-9.

15. Djibuti M, Gotsadze G, Mataradze G, et al. Influence of household demographic and socio-economic factors on household expenditure on tobacco in six New Independent States. BMC Public Health 2007;7:222.

16. Siahpush M. Socioeconomic status and tobacco expenditure among Australian households: results from the 1998-99 Household Expenditure Survey. J Epidemiol Community Health 2003;57:798-801.

17. Farrelly MC, Nonnemaker JM, Watson KA. The consequences of high cigarette excise taxes for low-income smokers. PLoS One 2012;7:e43838.

18. U.S. Department of Labor. 2015 Users' Document: Interview Survey Public-Use Microdata (PUMD) Consumer Expenditure: Bureau of Labor Statistics, Division of Consumer Expenditure Surveys. 2016.

19. U.S. Department of Labor. 2015 Response Rates: Interview and Diary Survey Consumer Expenditure Public Use Microdata: Bureau of Labor Statistics, Division of Consumer Expenditure Surveys. 2016.

20. U.S. Bureau of Labor Statistics. Consumer Expenditure Survey: frequently asked questions: U.S. Bureau of Labor Statistics. 2017 https://www.bls.gov/cex/csxfaqs.htm (accessed 14 Dec 2017).

21. U.S. Bureau of Labor Statistics. Consumer Expenditure Survey: Frequently Asked Questions: Unites States Department of Labor, 2018.

22. Perrins G, Nilsen D. Math calculations to better utilize CPI data: U.S. Bureau of Labor Statistics. 2017.

23. U.S. Bureau of Labor Statistics. Consumer Price Index Historical Tables for U.S. City Average: Department of Labor, 2017.

24. U.S. Census Bureau. Poverty thresholds: U.S. Census Bureau. 2016 https://www.census.gov/data/tables/time-series/demo/incomepoverty/historical-poverty-thresholds.html (accessed 02 May 2017).

25. U.S. Department of Labor. User's Guide to Income Imputation in the CE: Bureau of Labor Statistics, Division of Consumer Expenditure Surveys, 2006.

26. Korn EL, Graubard BI. Analysis of health surveys. New York: John Wiley \& Sons, 1999.

27. Levy PS, Lemeshow S. Sampling of populations: methods and applications: John Wiley \& Sons, 2013.

28. U.S. Bureau of Labor Statistics. Handbook of methods: consumer expenditure and income calculations. Washington D.C: U.S. Bureau of Labor Statistics, 2016. (accessed 17 Dec 2017).

29. StataCorp.. Stata Base Reference Manual Release 14. College Station, Texas: StataCorp LP, 2015

30. Smithson M, Merkle EC. Generalized linear models for categorical and continuous limited dependent variables. London: CRC Press, 2014.

31. Papke LE, Wooldridge JM. Panel data methods for fractional response variables with an application to test pass rates. $J$ Econom 2008;145(1-2):121-33

32. Papke LE, Wooldridge JM. Econometric methods for fractional response variables with an application to $401(\mathrm{k})$ plan participation rates. J Appl Econ 1996;11:619-32.

33. StataCorp. Stata Statistical Software: Release 14.1, MP Parallel Edition. College Station, TX: StataCorp LP, 2015.
34. Bee A, Meyer BD, Sullivan JX. The validity of consumption data: are the consumer expenditure interview and diary surveys informative?: National Bureau of Economic Research. 2012.

35. Businelle MS, Kendzor DE, Reitzel LR, et al. Mechanisms linking socioeconomic status to smoking cessation: a structural equation modeling approach. Health Psychol 2010;29:262-73.

36. Mathur C, Erickson DJ, Stigler MH, et al. Individual and neighborhood socioeconomic status effects on adolescent smoking: a multilevel cohort-sequential latent growth analysis. Am J Public Health 2013;103:543-8.

37. Jarvis MJ, Wardle J. Social patterning of individual health behaviours: the case of cigarette smoking. In: Marmot M, Wilkinson RG, eds. Social Determinants of Health. Oxford: Oxford University Press, 1999.

38. Paavola M, Vartiainen E, Haukkala A. Smoking from adolescence to adulthood: the effects of parental and own socioeconomic status. Eur J Public Health 2004;14:417-21.

39. Lindström M, Modén B, Rosvall M. A life-course perspective on economic stress and tobacco smoking: a population-based study. Addiction 2013;108:1305-14.

40. Sabelhaus J, Johnson DS, Ash S, et al. Is the consumer expenditure survey representative by income? SSRN Electronic Journal 2012.

41. Donovan RJ, Holman CD, Corti B, Corti CAJ, Jalleh G, et al. Faceto-face household interviews versus telephone interviews for health surveys. Aust N Z J Public Health 1997;21:134-40.

42. Arday DR, Tomar SL, Nelson DE, et al. State smoking prevalence estimates: a comparison of the Behavioral Risk Factor Surveillance System and current population surveys. Am J Public Health 1997;87:1665-9.

43. Siahpush M, Carlin JB, stress F. Financial stress, smoking cessation and relapse: results from a prospective study of an Australian national sample. Addiction 2006;101:121-7.

44. Siahpush M, Borland R, Yong HH. Sociodemographic and psychosocial correlates of smoking-induced deprivation and its effect on quitting: findings from the International Tobacco Control Policy Evaluation Survey. Tob Control 2007;16:e2.

45. Kendzor DE, Businelle MS, Costello TJ, et al. Financial strain and smoking cessation among racially/ethnically diverse smokers. Am J Public Health 2010;100:702-6.

46. Siahpush $\mathrm{M}$, Yong $\mathrm{HH}$, Borland $\mathrm{R}$, et al. Smokers with financial stress are more likely to want to quit but less likely to try or succeed: findings from the International Tobacco Control (ITC) Four Country Survey. Addiction 2009;104:1382-90.

47. Siahpush M, Wakefield MA, Spittal MJ, et al. Taxation reduces social disparities in adult smoking prevalence. Am J Prev Med 2009;36:285-91.

48. Farrelly MC, Engelen M. Cigarette prices, smoking, and the poor, revisited. Am J Public Health 2008;98:582-3.

49. Clinical Practice Guideline Treating Tobacco Use and Dependence 2008 Update Panel, Liaisons, and Staff. A clinical practice guideline for treating tobacco use and dependence: 2008 update. A U.S. Public Health Service report. Am J Prev Med 2008;35:158-76.

50. Partos TR, Gilmore AB, Hitchman SC, et al. Availability and use of cheap tobacco in the United Kingdom 2002-2014: findings from the international tobacco control project. Nicotine Tob Res 2018;20:ntx108.

51. Hiscock R, Branston JR, McNeill A, et al. Tobacco industry strategies undermine government tax policy: evidence from commercial data. Tob Control 2017:tobaccocontrol-2017-053891.

52. White VM, Hayman J, Hill DJ. Can population-based tobacco-control policies change smoking behaviors of adolescents from all socioeconomic groups? Findings from Australia: 1987-2005. Cancer Causes Control 2008;19:631-40.

53. Levy DT, Mumford EA, Compton C. Tobacco control policies and smoking in a population of low education women, 1992-2002. Journal of Epidemiology \& Community Health 2006;60:ii20-ii26.

54. Durkin SJ, Biener L, Wakefield MA. Effects of different types of antismoking ads on reducing disparities in smoking cessation among socioeconomic subgroups. Am J Public Health 2009;99:2217-23.

55. Guillaumier A, Bonevski B, Paul C, et al. Socioeconomically disadvantaged smokers' ratings of plain and branded cigarette packaging: an experimental study. BMJ Open 2014;4:e004078.

56. Dinno A, Glantz S. Tobacco control policies are egalitarian: a vulnerabilities perspective on clean indoor air laws, cigarette prices, and tobacco use disparities. Soc Sci Med 2009;68:1439-47.

57. Hackshaw L, McEwen A, West R, et al. Quit attempts in response to smoke-free legislation in England. Tob Control 2010;19:160-4.

58. Hahn EJ, Rayens MK, Butler KM, et al. Smoke-free laws and adult smoking prevalence. Prev Med 2008;47:206-9. 